\title{
Del OBJETO AL Símbolo: ASPECTOS COGNITIVOS Y SOCIALES DEL CONOCIMIENTO INFANTIL SOBRE LAS IMÁGENES*
}

\section{FROM OBJECT TO SYMBOL: COGNITIVE AND SOCIAL ASPECTS OF CHILDREN'S KNOWLEDGE OF PICTURES}

\author{
Analía M. Salsa ${ }^{* *}$ Y Romina A. Vivaldi ${ }^{* * *}$ \\ *Trabajo realizado en el marco del proyecto PIP N 0355 del Consejo Nacional de Investigaciones \\ Científicas y Técnicas (CONICET). Directora del proyecto: Dra. Analía M. Salsa. \\ ${ }^{*}$ Doctora en Psicología. Miembro de la Carrera del Investigador Científico del Consejo Nacional de \\ Investigaciones Científicas y Técnicas (CONICET). E-Mail: salsa@irice-conicet.gov.ar \\ ${ }^{* * *}$ Psicóloga. Becaria Doctoral del Consejo Nacional de Investigaciones Científicas y Técnicas \\ (CONICET). E-Mail: vivaldi@irice-conicet.gov.ar \\ Instituto Rosario de Investigaciones en Ciencias de la Educación ( IRICE).
}

Bv. 27 de Febrero 210 bis

(2000) Rosario. República Argentina

\section{RESUMEN}

Desde temprano en sus vidas, los niños están expuestos a una variedad de representaciones $f i$ gurativas en fotografías, libros, en la televisión y el video. Este artículo postula que a pesar de la similitud perceptual entre estas imágenes y sus referentes, su comprensión es un proceso complejo en el que participan mecanismos perceptuales, cognitivos y sociocognitivos.

La primera parte del artículo revisa investigaciones que han identificado los principales hitos evolutivos en la comprensión de las representaciones figurativas y los mecanismos perceptuales y cognitivos que subyacen a este proceso. Este análisis permite proponer tres fases en este desarrollo (pre-simbólica, simbólica y postsimbólica) desde el nacimiento hasta el comienzo de los años escolares.

La segunda parte examina la influencia en la comprensión de factores relacionados con el contexto social, específicamente la experiencia simbólica y la intención del creador y/o el usuario de una imagen. De esta manera, las habili- dades para la cognición social y el aprendizaje cultural son también cruciales en el conocimiento y uso de representaciones figurativas.

Palabras clave: Representaciones figurativas; Comprensión; Representación dual; Experiencia simbólica; Intencionalidad.

\section{ABSTRACT}

From early in infancy, children are exposed to a wide variety of figurative representations; they read picture books and magazines with their parents and look at family photos and images on television and video.

Figurative representations are a particular type of external representations. An external representation is "something that someone intends to stand for or represent something other than itself" (DeLoache, 1995, p. 109). Figurative representations are two-dimensional representations highly similar to their referents; however, this article 
develops the idea that even though this perceptual similarity, figurative representations are not transparent objects for very young children. Understanding the dual nature of pictures, that they are things in themselves and communicate meaning by referring to some other reality, is a lengthy and complex developmental process influenced and determined by perceptual, cognitive and socialcognitive mechanisms.

The first part of the article reviews studies that have identified the major milestones in pictorial comprehension and discusses the perceptual (discrimination, categorization) and cognitive mechanisms (concept formation, analogical reasoning, representational strategies) underlying this process. This analysis allows us to propose three phases of development from birth to the beginning of the school period: (1) a pre-symbolic phase, between 0 and 18 months of age, when infants mainly take a manipulative stance toward pictures; (2) a symbolic phase, between two and three years, when children comprehend and use the symbolic link between pictures and referents; and (3) a postsymbolic phase, after four years, when children understand that the contents of pictures remain stable despite any change made to the real objects they depict.

The second part of the article examines the influence of social factors on pictorial comprehension, specifically symbolic experience and the intention of the creator and/or user of a picture. The supporting role of social factors in symbolic development has long been demonstrated in the domain of language (see Baldwin, 2000; Tomasello, 1999, 2003); in contrast, very little is known about the impact of social cognitive mechanisms (cultural learning, intentionality) in children's knowledge of pictures.

DeLoache $(1995,2002)$ proposed that with age children gain experience with symbols and develop a general expectation or readiness to look for and detect symbolic relations among entities. However, this paper presents evidence that symbolic experience has a crucial social dimension; supportive contexts that highlight the relation between pictorial symbols and their referents in close social interactions facilitate children's comprehension of images (Callaghan \& Rankin, 2002; Szechter \& Liben, 2004). Cross-cultural and social differences in the age of onset of symbolic comprehension also support this hypothesis (Callaghan et al., 2011; Salsa, in press).

Intention is both necessary and sufficient to establish a symbolic relation (Werner \& Kaplan, 1963); understanding intentionality is especially important for interpreting symbols because their meaning is assigned by the symbol creator or user. There is abundant evidence that young infants (12 months) are sensitive to basic aspects of the intentions of adults who act on objects in the world, and that older infants (18-24 months) begin to discern the more subtle communicative intentions of adults found in the flow of actions found in social exchanges using language symbols (Tomasello, 2003). A few studies have explored whether children are sensitive to another person's intention to represent when they name drawings or use photographs in a search task (Bloom \& Markson, 1998; Gelman \& Ebeling, 1998; Preissler \& Bloom, 2008; Salsa \& Peralta, 2007). Nevertheless, these studies show that children's ability to read intentions is another privileged route towards symbolic understanding.

Keywords: Figurative representations; Comprehension; Dual representation; Symbolic experience; Intentionality.

\section{INTRODUCCIÓN}

Fotografías en álbumes familiares, ilustraciones y dibujos en libros, revistas y carteles, imágenes de televisión y video forman parte de la vida de los niños desde los inicios de su desarrollo. Gracias a las imágenes, además de representar la realidad, es posible registrar y conservar información a lo largo del tiempo, aprender conocimientos, regular y planificar el comportamiento y comunicar los más variados tipos de información.

Las imágenes son instrumentos de un enorme valor cognitivo, cultural y educativo; su conocimiento y uso modifica en profundidad las capacidades cognitivas y permite la adaptación cultural de los niños a su grupo social de referencia. Las imágenes 
apoyan y enriquecen el aprendizaje: las ilustraciones en los libros infantiles son utilizadas por los adultos para que los niños adquieran desde sus primeras palabras hasta información acerca de seres, lugares o acontecimientos a los que no es posible tener acceso directo.

El interés de este trabajo radica en el estudio de la emergencia y el curso temprano de la comprensión de las representaciones basadas en la imagen o representaciones figurativas.

Las representaciones figurativas constituyen un tipo particular de representaciones externas. El término representaciones externas refiere a aquellas "entidades que alguien propone para representar una cosa a partir de algo diferente" (DeLoache, 1995, p. 109). En esta definición confluyen dos afirmaciones clásicas: la de Goodman (1976) respecto a que virtualmente cualquier entidad puede servir a una función simbólica y la de Werner y Kaplan (1963) acerca de que la simbolización implica "un acto intencional de referencia denotativa" (p. 21). Ahora bien, esta definición puede aplicarse a cualquier forma externa de representación. Lo que distingue a las representaciones figurativas del lenguaje oral es que son marcas desplegadas en el espacio y que por ello tienen una determinada forma directamente perceptible por la vista; figurativo remite precisamente a la idea de figura o forma. A diferencia de la escritura, la notación matemática y la notación musical, la organización espacial de las marcas establecen una correspondencia clara con las propiedades geométricas y espaciales del referente (Martí, 2003).

Esta correspondencia puede ser una relación de fuerte semejanza, como ocurre con algunos dibujos, las fotografías y las imágenes audiovisuales, o bien el resultado de un proceso de selección y esquematización de algunas propiedades del referente, como en los planos y mapas.

Este estudio centró su interés en imágenes altamente similares a sus referentes, particularmente las fotografías y los dibujos figurativos. La similitud perceptual ha llevado a plantear que estas imágenes son procesadas por el sistema cognitivo como si se tratara de los objetos del mundo físico que representan, por lo que su conocimiento no requeriría de aprendizaje específico (Dirks \& Gibson, 1977; Hochberg, 1997).

El presente trabajo adopta una perspectiva diferente. En primer término se asume que las imágenes no son objetos transparentes para los niños muy pequeños, quienes deben recorrer un largo y complejo camino desde el reconocimiento perceptual de los elementos representados hasta la comprensión de que las imágenes son símbolos que les sirven a ellos mismos y a los demás para representar objetos y eventos, reales o imaginarios. En la primera parte se presentan las principales pautas evolutivas de la comprensión de las representaciones figurativas y se discuten los posibles mecanismos perceptuales y cognitivos que subyacen a este proceso. Esta revisión y análisis permiten identificar tres momentos bien diferenciados desde el nacimiento hasta el comienzo de los años escolares en el desarrollo del conocimiento sobre las imágenes.

En segundo término se examina el lugar que ocupan los procesos sociales en la ontogenia de la comprensión de las imágenes como símbolos. Es evidente que para aprender a leer, a escribir o a sumar, los niños precisan la intervención de otras personas más competentes que sepan interpretar la escritura o los numerales. Sin esta ayuda directa, la adquisición de estos sistemas externos de representación no sería posible. Sin embargo, en el estudio del desarrollo de la comprensión de las imágenes la influencia de factores sociales ha sido relegada por el predominio de perspectivas teóricas que enfatizan el papel de la memoria, la percepción, las habilidades conceptuales y representacionales u otros factores internos (KarmiloffSmith, 1992; Morra, 2008; Piaget \& Inhelder, 1956).

En la segunda parte del artículo se ofrece el análisis de una serie de estudios que investigan el impacto de la experiencia simbólica, mediada por los adultos del entorno $\mathrm{y}$ de la intencionalidad del dibujante y/o del 
usuario de una imagen. El examen del papel de ambos factores permite ilustrar cómo el contexto social y el contexto cognitivo de los niños trabajan en forma conjunta en el desarrollo de la comprensión simbólica. A partir de las investigaciones analizadas se concluye que las habilidades para la cognición social y el aprendizaje cultural son también cruciales en el camino del objeto al símbolo en la adquisición del conocimiento sobre las imágenes.

\section{ASPECTOS EVOLUTIVOS Y MECANISMOS INVOLU- CRADOS EN LA COMPRENSIÓN DE IMÁGENES}

Si un adulto estuviese en un salón de lectura y apareciera súbitamente la diapositiva de un elefante en posición de ataque frente a él, seguramente permanecería sentado sin inmutarse (Deregowski, 1989). Para De Loache (2002) esto sucede al menos por tres razones: perceptualmente, la ausencia de tridimensionalidad da cuenta de que no es un elefante real; conceptualmente, el adulto categoriza la diapositiva como una imagen y por ello conoce que el elefante que aparece en ella no es real; por último, pragmáticamente, él sabe que es poco probable que un elefante aparezca en una biblioteca.

Gran parte de este conocimiento se adquiere gradualmente en los primeros años de vida y es fruto de la acción conjunta de capacidades perceptuales y cognitivas. Este trabajo postula que es posible identificar tres momentos en este proceso:

1.- una fase pre-simbólica que abarca el primer año y medio de vida, cuando las imágenes son tratadas por los niños sólo como objetos físicos manipulables,

2.- una fase simbólica, entre los 2 y 3 años, momento en que los niños descubren que las imágenes son símbolos de la realidad y

3.- una fase post-simbólica, después de los 4 años, cuando el conocimiento de las imágenes ya es explícito y meta-representacional.
FASE PRE-SIMBÓLICA: LAS IMÁGENES COMO OBJETOS DE MANIPULACIÓN

Está documentado ampliamente que los bebés desde los 2 meses de vida son capaces de reconocer rostros, objetos y formas abstractas en fotografías y dibujos (Barrera \& Maurer, 1981; DeLoache, Strauss \& Maynard, 1979; Slater, Rose \& Morison, 1984). En estos momentos tempranos, aún con muy pocas experiencias directas con imágenes, los niños discriminan entre estímulos bidimensionales y tridimensionales y 'ven' a través de una imagen a su referente. Habilidades similares de procesamiento perceptivo de las imágenes estarían presentes en los mamíferos en general, aunque la mayor parte de evidencia empírica proviene de experimentos conducidos con simios y monos (Bovet \& Vauclair, 2000).

Hasta aproximadamente los 18 meses, los niños tratan a las imágenes sólo como objetos físicos: sus conductas frente a ellas son predominantemente de manipulación. Por ejemplo, Perner (1991) reportó el esfuerzo de su hijo de 16 meses por calzar su pie dentro de la fotografía de un zapato. Para explorar sistemáticamente la existencia y el significado de estas conductas, De Loache, Pierroutsakos, Uttal, Rosengren y Gottlieb (1998) presentaron a niños de 9 a 18 meses un libro con fotografías a color de distintos objetos y observaron sus reacciones frente a las imágenes. Los resultados fueron consistentes con las anécdotas de Perner. Los bebés de 9 meses frotaban, acariciaban, golpeaban y hasta intentaban despegar los objetos representados en las páginas del libro como si fuesen objetos tridimensionales (ver también Callaghan, Rochat, Mac Gillivray \& MacLellan, 2004; Yonas, Granrud, Chov \& Alexander, 2005).

El modo en que los bebés exploran los objetos representados se relaciona con la similitud perceptual entre la imagen y su referente. Pierroutsakos y DeLoache (2003) mostraron que la exploración manual de los bebés de 9 meses ocurría mayormente con fotografías a color y con mucha menos frecuencia con dibujos en blanco y negro. Por 
tanto, en este momento del desarrollo, cuanto más directamente reflejan las imágenes a sus referentes, más los bebés las exploran manualmente.

Si los bebés discriminan entre los estímulos bidimensionales y tridimensionales, ¿cómo explicar la exploración manual de las imágenes? Sería posible pensar que las fotografías a color activan en los niños las representaciones mentales de las categorías de objeto a las que refieren, junto con los esquemas motores para interactuar con ellos. Al mismo tiempo, no obstante, los elementos representados proveen pocas pistas visuales acerca de la tridimensionalidad de los objetos reales. Entonces, los bebés manipularían las imágenes no necesariamente porque crean que los objetos representados son los objetos reales sino porque encontrarían a las imágenes sorprendentemente desafiantes. Las tocan y frotan para explorar qué clase de objetos son las imágenes y cómo se relacionan con sus referentes.

Otra característica de esta fase pre-simbólica es que los niños ignoran una de las convenciones más básicas acerca de las imágenes: su orientación. Pierroutsakos, DeLoache, Gound y Bernard (2005) mostraron que los niños de 18 meses no demuestran preferencia frente a una imagen en posición vertical o en posición invertida, identificando rápidamente el objeto representado sin importar su orientación. Sin embargo, esta conducta no se aplica a los objetos tridimensionales: si los observan en posición invertida, corrigen su orientación. Para las autoras, el conocimiento de la orientación de las imágenes no sería producto de cambios en el procesamiento perceptivo sino del aprendizaje gradual de una convención social que determina que las representaciones figurativas deben respetar una posición particular.

Durante este primer año y medio de vida, distintos mecanismos favorecen el conocimiento de las diferencias y similitudes entre las representaciones figurativas y sus referentes tridimensionales. Rochat y Callaghan (2005) destacan la influencia de la diferenciación perceptual, la categorización per- ceptual, la formación de conceptos y el razonamiento por analogía. La diferenciación perceptual permitiría a los niños utilizar el registro de las características constantes de los objetos para discriminar precozmente los objetos bidimensionales de los tridimensionales. La categorización perceptual y la formación de conceptos posibilitarían agrupar a las imágenes en una clase especial de objetos. Por último, el razonamiento por analogía facilitaría el conocimiento de las relaciones entre imágenes y referentes y la transferencia de conocimiento entre ambos para aprender sus similitudes y diferencias: el dibujo de una manzana es al mismo tiempo similar y distinto a la fruta real que representa.

El efecto de la edad en el tratamiento de las imágenes como objetos de manipulación sigue un desarrollo en ' $U$ ' invertido: se incrementa fuertemente entre los 4 y 9 meses y decrece paulatinamente entre los 9 y 18 meses. A partir de esta edad, los niños reemplazan las conductas de manipulación de las imágenes por su contemplación, el señalamiento de las mismas con sus dedos y, a veces, su nombramiento. Esto podría suceder debido a los avances en el control inhibitorio (Diamond, 2002) que ayudarían a restringir el impulso a responder ante el objeto representado como si fuese un objeto real. Pero, además, al crecer en un ambiente rico en imágenes, los niños observan cómo las personas interactúan con ellas, las miran, señalan y hablan, las utilizan como un medio de comunicación ya sea para solicitar o brindar información. Esta nueva orientación hacia las imágenes es el punto de partida para la comprensión infantil de su naturaleza simbólica.

\section{FASE SIMBÓLICA: LAS IMÁGENES COMO OBJETOS DE CONTEMPLACIÓN}

Los niños comienzan a comprender que las fotografías y los dibujos representan un referente específico en la realidad finalizando su segundo año de vida. Preissler y Carey (2004) realizaron un sencillo experi- 
mento en el que enseñaban a niños de 18 y 24 meses el nombre de un objeto desconocido para ellos ('batidor') emparejando este nombre repetidas veces con un dibujo del objeto. Luego, pedían a los niños que señalaran el 'batidor'. Los niños señalaron el objeto o bien el dibujo junto con el objeto, nunca indicaron solamente la imagen. De esta manera muy simple fue posible observar que a partir de los 18 meses los niños interpretan la función referencial de las imágenes; al observar a un adulto nombrar una imagen, comprenden que el nombre refiere al objeto representado y no a la imagen en sí misma (ver también Ganea, Allen, Butler, Carey \& DeLoache, 2009).

Estudios recientes muestran que esta comprensión temprana dependería de la naturaleza de las imágenes. Utilizando un procedimiento similar al diseñado por Preissler y Carey (2004), Ganea, Bloom Pickard y DeLoache (2008) examinaron si la similitud perceptual influía cuando niños de 15 y 18 meses debían aprender el nombre de un objeto en una sesión de 'lectura' de un libro de imágenes y transferir ese nombre a su referente y a otros ejemplares del mismo objeto. Utilizaron tres tipos de libros: uno con fotografías, otro con dibujos figurativos y uno con caricaturas que distorsionaban la forma del objeto, todos a color. Las autoras observaron que los niños más pequeños fueron exitosos en la tarea con los libros con fotografías y dibujos, mientras que los de 18 meses también lo fueron con caricaturas. De este modo, altos niveles de similitud perceptual harían la relación simbólica más transparente para los niños más pequeños, quienes así podrían transferir información aprendida de las representaciones a sus referentes.

Simcock y DeLoache (2006) informaron el mismo patrón de resultados en una tarea en la que niños de 18, 24 y 30 meses tenían que imitar una serie de acciones ilustradas en un libro y usar la información aprendida para construir un objeto. En este caso, los libros poseían fotografías y dibujos a color y dibujos en lápiz negro sobre cómo un niño confeccionaba un sonajero con un frasco, un palo y una pelota. La similitud perceptual facilitó la resolución de la tarea a los 18 y 24 meses; únicamente los niños de 30 meses fueron exitosos con los tres tipos de imágenes.

Alrededor de los 30 meses los niños demuestran signos claros de que comprenden la naturaleza simbólica de las imágenes y de que son capaces de usarlas como fuente de información. DeLoache (1987) diseñó una tarea de búsqueda en la que los niños deben utilizar la información provista por una representación figurativa para resolver un problema (encontrar un objeto escondido). En esta tarea la experimentadora escondía un juguete en un mueble de una habitación (por ejemplo, debajo de un sillón) sin que los niños observaran este evento. Luego, mostraba a los niños una fotografía del escondite y les pedía que fueran a la habitación a buscar el juguete en ese lugar. Los niños de 30 meses, no así los de 24 meses, utilizaron la información provista por la fotografía para encontrar el juguete (DeLoache \& Burns, 1994; Peralta \& Salsa, 2011). Idénticos resultados fueron obtenidos cuando la información sobre la ubicación del juguete se transmitió mediante un dibujo en lápiz negro del escondite (DeLoache, 1991). Las dificultades de los niños de 24 meses en la tarea de búsqueda fueron replicadas utilizando una imagen de video en lugar de fotografías (Schmitt \& Anderson, 2002; Troseth, 2003; Troseth \& DeLoache, 1998).

Harris, Kavanaugh y Dowson (1997) emplearon otra clase de tarea, una prueba de correspondencias en la que los niños debían seleccionar la imagen de un objeto referente. Los niños observaban acciones reales e imaginarias ejecutadas por un experimentador, quien arrojaba salsa de tomate sobre un animal de juguete o hacía 'como si' tirara algo sobre él. La tarea consistía en elegir cuál fotografía, entre tres posibles, reflejaba el resultado de la acción del experimentador mientras el juguete permanecía a la vista de los niños. Recién a los 30 meses los niños fueron capaces de seleccionar la fotografía correcta en ambas condiciones experimentales. 
Los estudios hasta aquí revisados, aunque emplean distintos tipos de tareas (de aprendizaje de palabras, de búsqueda y de correspondencias imagen - objeto), coinciden en señalar que entre los 18 y 30 meses se produce un avance gradual en la comprensión de la relación simbólica imagen - referente. Ahora bien, ¿cuál es la naturaleza de esta comprensión y cuáles serían sus limitaciones?

Una adquisición central en el conocimiento infantil de las imágenes es reconocer el llamado problema de la representación dual (DeLoache, 1987). Las imágenes poseen una naturaleza doble; son objetos con determinadas características tangibles y simultáneamente representaciones que refieren a otra cosa. Un dibujo de un león se caracteriza por el tamaño y la textura del papel, por los colores de los materiales utilizados para su confección. A esta dimensión material se le agrega una dimensión representacional, ya que el dibujo no es un león pero lo simboliza. El problema de la representación dual está en la dificultad de los niños pequeños para activar al mismo tiempo las representaciones mentales de ambas dimensiones de una imagen.

Tare, Chiong, Ganea y DeLoache (2010) demostraron que si se exacerban las propiedades físicas de un dibujo, por ejemplo presentando un libro con figuras desplegables para manipular, aún hasta los 36 meses los niños tienen dificultades para establecer la relación entre estas representaciones y la realidad. En este caso, las características físicas atractivas de la imagen oscurecerían el reconocimiento de su naturaleza dual.

La comprensión que se observa entre los 30 y 36 meses es aún frágil. En la fase simbólica, los niños comprenden la relación representación figurativa - referente basándose en la similitud perceptual pero también en el nombre de los objetos representados. Esta hipótesis fue explorada por Callaghan (2000) con niños de 30 y 36 meses usando una tarea de correspondencias símbolo-referente en la que los niños debían usar dibujos que diferían en color y perspectiva para escoger un objeto y guardarlo dentro de una caja. Los objetos tenían un nombre familiar o desconocido por los niños. A los 30 meses los niños establecieron la relación con el referente solamente con las imágenes más realistas y si conocían el nombre del objeto representado. Sería posible pensar que un mapeo analógico en base a relaciones estructurales superficiales (Gentner, 2010) estaría favoreciendo el acceso a la relación simbólica.

Cuando los niños comienzan a prescindir de pistas visuales y lingüísticas, se produce un cambio cualitativo fundamental en su teoría sobre las imágenes: reconocen la existencia independiente de las representaciones y sus referentes e incorporan las intenciones y estados mentales de las personas que las crean y utilizan.

\section{FASE POST-SIMBÓLICA: MÁS ALLÁ dE LA REPRESEN-} TACIÓN DUAL

Una serie de nuevas capacidades aparecen luego de los 48 meses. Los niños de esta edad confunden bajo ciertas circunstancias las propiedades de una imagen y de su referente: piensan que sacudir una fotografía de bloques apilados ocasionaría que éstos se caigan (Flavell, J.H., Flavell, E.R., Green \& Korfmacher, 1990). Zaitchik (1990) le mostró a niños de distintas edades una muñeca y su fotografía. Luego, volteó la fotografía, cambió la muñeca de posición y preguntó a los niños si el cambio en la muñeca se vería reflejado en la imagen. Sorprendentemente, sólo los niños mayores de 48 meses dijeron que no. Robinson, Nye y Thomas (1994) utilizaron un procedimiento similar pero en lugar de tomar una foto de la muñeca la dibujaban frente a los niños; la hipótesis fue que los niños podrían estar más familiarizados con la producción de un dibujo que con la toma de una fotografía pudiendo facilitarse así la tarea. La muñeca poseía una etiqueta con una oveja dibujada en ella. Luego, la experimentadora intercambiaba la etiqueta por una con un mono y preguntaba a los niños si la etiqueta que aparecía en el dibujo de la muñeca también 
había cambiado. Los niños de 36 y 48 meses contestaron correctamente con mayor frecuencia que en el estudio de Zaitchik, pero aún muchos encontraron dificultades en la comprensión de la existencia independiente del dibujo y su referente.

Estos ejemplos muestran que un aspecto importante del conocimiento sobre las imágenes es entender que el contenido de una fotografía o de un dibujo permanece estable a pesar de los cambios que pueda sufrir el objeto representado. La emergencia de esta habilidad coincide con la aparición de la teoría representacional de la mente (Gopnik, 1996; Perner, 1991). Entre los 48 y 60 meses los niños pueden coordinar su capacidad para interpretar una imagen con la capacidad para comparar situaciones, lo que trae como consecuencia la comprensión de que una imagen puede representar una situación diferente de la que ellos están contemplando.

En este momento del desarrollo, el conocimiento de las imágenes incorpora las intenciones, emociones y pensamientos de los otros (Callaghan \& Rochat, 2003; Freeman $\&$ Sanger, 1993). Los niños de 60 meses (5 años) interpretan un dibujo teniendo en cuenta la edad de su dibujante (si es un adulto, un niño mayor o menor que ellos) y su estado emocional mientras dibuja (agitado o calmado). Entre esta edad y los 7 años son capaces de relacionar la emoción expresada en un dibujo (alegría y tristeza) con el estado emocional del artista.

A partir de todo lo expuesto es posible afirmar que hasta con imágenes altamente similares a sus referentes, su naturaleza simbólica no es evidente para los niños pequeños. El conocimiento de las representaciones figurativas sigue pautas de adquisición propias determinadas por una serie de mecanismos cognitivos y precisa un largo recorrido para desembocar en una completa y profunda comprensión de las imágenes. Ahora bien, el encuentro de los niños con estas representaciones no se da en solitario sino mediado por los adultos del entorno, quienes les enseñan qué son las imágenes y cómo y para qué utilizarlas. Frente a una fotografía, por ejemplo, el adulto señala las personas y los objetos que aparecen en ella y dice sus nombres, mientras el niño dirige su mirada atenta a los elementos representados y los señala y nombra. Como sostiene Vygotsky (1978), el contexto provee las herramientas simbólicas y las interacciones sociales ofrecen a los niños oportunidades para aprender a utilizarlas. Este proceso interactivo ayuda a desarrollar habilidades cognitivas nuevas.

\section{EL CONTEXTO SOCIAL: EXPERIENCIA SIMBÓLICA E INTENCIONALIDAD}

La información social es una ruta privilegiada para conocer el mundo; los niños aprenden palabras y habilidades cognitivas a través de la información que brindan los adultos y de las conductas que indican un foco compartido de interés como mirar, señalar y dar respuestas contingentes (Baldwin, 2000; Tomasello, 2003). Tomasello (1999) denominó aprendizaje cultural al mecanismo que permite a los bebés humanos explotar el conocimiento y las habilidades de sus congéneres. El papel del aprendizaje cultural en sus distintas formas (por imitación, instrucción y colaboración) ha sido demostrado repetidamente en investigaciones sobre adquisición del lenguaje; no obstante, ha recibido una atención escasa en los estudios sobre comprensión de imágenes. La tesis que aquí se defiende es que las experiencias con los adultos utilizando estos símbolos restringen la construcción individual en el desarrollo del conocimiento sobre las imágenes.

\section{EXPERIENCIA SIMBÓLICA: LAS IMÁGENES Y LOS OTROS}

La experiencia simbólica ha sido propuesta por DeLoache $(1995,2002)$ en términos de los efectos acumulativos de la exposición a diferentes clases de representaciones externas y a diversos ejemplares de un mismo tipo de representación. De esta forma, este factor parecería quedar reducido a los efectos de la edad; a medida que los niños crecen, incrementan sus experiencias 
con representaciones externas y desarrollan una capacidad general (sensibilidad simbólica) para buscar y reconocer relaciones simbólicas entre entidades.

Autoras como Liben (1999) y Callaghan (2008) ofrecen una mirada diferente; además del contacto con símbolos, el apoyo social y las experiencias infantiles dibujando y aprendiendo técnicas gráficas específicas serían componentes centrales de la experiencia simbólica. Del mismo modo que con otros sistemas simbólicos, el desarrollo del conocimiento sobre las imágenes depende del apoyo cultural en forma de andamiaje que ofrecen los adultos al usar las imágenes como símbolos en las interacciones con bebés y niños pequeños.

Esta perspectiva ha comenzado a recibir recientemente apoyo empírico. En un estudio longitudinal, Callaghan y Rankin (2002) expusieron a niños de 28 meses a un entrenamiento en el que observaban a un adulto dibujando para examinar si esta experiencia podía facilitar la emergencia de la comprensión en niños que todavía no eran capaces de usar simbólicamente imágenes. Las autoras encontraron que después de dos meses los niños que habían recibido las sesiones semanales con el adulto dibujando (grupo experimental) se desempeñaban mejor en tareas de comprensión de dibujos que los niños de un grupo control. Este grupo no tuvo un rendimiento similar al del grupo experimental hasta el quinto mes de la investigación cuando recibieron la misma experiencia. Así, la exposición repetida a un experto que enseña a los niños la relación dibujo - referente puede acelerar la aparición de la comprensión simbólica.

Szechter y Liben (2004) investigaron cómo los padres guiaban a sus hijos de 36 y 60 meses en la comprensión de un libro de ilustraciones (Zoom) en el que se representaban objetos desde una distancia cercana hacia distancias cada vez más lejanas. Los datos observacionales revelaron una variedad muy rica de estrategias parentales para promover la comprensión infantil de estas representaciones, desde realizar comentarios sobre las relaciones espaciales entre di- bujos que aparecían en distintas páginas del libro hasta acercar y alejar el rostro de los niños para demostrarles las consecuencias perceptuales de cambiar la distancia visual. Más importante aún, la calidad de las estrategias adultas estuvo asociada a la ejecución independiente de los niños mayores en tareas de comprensión con fotografías.

Diferencias culturales y sociales dentro de un mismo grupo cultural en la emergencia de la fase simbólica contribuyen a postular la relación entre aprendizaje cultural y experiencia simbólica. Callaghan y colaboradores (2011) investigaron diferencias interculturales en la comprensión y la producción de dibujos figurativos en niños de 24 a 36 meses provenientes de familias urbanas en Canadá y de dos comunidades rurales pequeñas en Perú e India. Encontraron que los niños canadienses, quienes tenían mayor cantidad de experiencias con variados tipos de imágenes, mostraron habilidades simbólicas de comprensión y producción entre un año y un año y medio antes que los otros dos grupos de niños. De acuerdo a los datos recabados en entrevistas con las madres, los niños de las comunidades rurales en Perú e India sólo tenían algún calendario e ilustraciones religiosas en sus hogares.

En otro estudio (Salsa, en prensa) se observaron patrones evolutivos disímiles en la comprensión de dibujos y fotografías en función del nivel socioeconómico (NSE). Niños urbanos de 30 a 42 meses de NSE medio y bajo en Argentina debían seleccionar entre cinco imágenes la fotografía a color o el dibujo en lápiz negro de una serie de objetos muy simples. Los resultados mostraron un fuerte impacto del NSE, reflejado en una asincronía en la emergencia de la comprensión; la similitud perceptual influyó únicamente en el NSE bajo. Mientras que los niños de NSE medio comprendieron la relación entre ambos tipos de imágenes y sus referentes a los 30 meses, los niños de NSE bajo demostraron comprender la naturaleza simbólica de las fotografías antes que la de los dibujos, a los 36 y 42 meses respectivamente. En esta investigación, los niños de ambos grupos sociales tenían contacto con fo- 
tografías e imágenes de televisión y DVD; sin embargo, en los hogares de NSE bajo había menor cantidad y variedad de libros y revistas con ilustraciones infantiles y las madres no acostumbraban a interactuar con sus hijos con libros o mientras ellos dibujaban.

Ahora bien, en línea opuesta a estos resultados, durante la fase pre-simbólica bebés de 9 meses de una comunidad rural de la Costa de Ivory en África Occidental exploraron manualmente fotografías a color de igual forma que bebés americanos urbanos de la misma edad (DeLoache et al., 1998). Se podría pensar entonces que los efectos de la experiencia simbólica comienzan a evidenciarse en la transición a la fase simbólica, cuando los niños aprenden en los intercambios con los adultos que las imágenes son objetos de contemplación y no para la acción.

A medida que los niños incrementan sus experiencias en actividades sociales con las imágenes creadas y utilizadas por otros, construyen conocimientos acerca de qué son las imágenes y para qué sirven. Este aprendizaje cultural es en parte posible gracias a la habilidad de los niños para entender a sus congéneres como seres dotados de una vida mental e intencional.

INTENCIONALIDAD: LAS IMÁGENES Y LA MENTE DE LOS OTROS

Las habilidades de compartir intenciones son indispensables para el ejercicio de actividades de colaboración y atención conjunta $\mathrm{y}$ como motivación social para ayudar $\mathrm{y}$ compartir con otros (Tomasello, 1999, 2003; Woodward, 1999). Dos hitos evolutivos marcan el desarrollo de estas habilidades: el primero, alrededor de los 9 meses, cuando los niños descubren que las personas son agentes intencionales, que la conducta humana es intencional; el segundo, a los 48 meses, cuando con el surgimiento de la teoría de la mente los niños descubren que las personas son agentes mentales con pensamientos y creencias que pueden diferir de la realidad.
La comprensión de los otros como seres intencionales es crucial en el aprendizaje humano y posee un lugar central en el conocimiento y uso de representaciones externas. Como se mencionó al inicio de este artículo, lo que determina que una entidad sea una representación es la intención humana; un objeto ostensivo directamente observable se convierte en una representación como resultado de que una persona lo cree o use para denotar o para referir a algo. Las representaciones externas, además de su dimensión representativa, poseen una dimensión intencional y comunicativa que debe ser reconocida para su uso convencional (Namy \& Waxman, 2005; Tomasello, 1999).

La intencionalidad "es un estado mental que un agente utiliza para movilizar un conjunto de procesos que este agente espera lleven a cabo su intención. Si el proceso no funciona, el producto final puede ser malinterpretado o incluso no interpretado" (Freeman \& Adi-Japha, 2008, p.112). En el caso de las imágenes, la intención es una pista que facilita la comprensión de las formas que se despliegan sobre el papel, mientras que las formas son una pista hacia la intención del artista.

Bloom y Markson (1998) señalan que "los niños nombran a una imagen que se parece a un pájaro 'pájaro' no simplemente porque ésta se parezca a un pájaro, sino porque su apariencia hace que sea probable que haya sido creada con la intención de representar un pájaro. En general, la apariencia y la forma en particular son vistas como una excelente señal de la intención” (p. 203).

Un grupo de investigaciones examinaron las relaciones entre intención e imágenes con niños pequeños. Gelman y Ebeling (1998) pidieron a niños de 30 a 48 meses y a adultos que nombraran objetos representados en dibujos en lápiz negro luego de informarles que éstos habían sido creados intencionalmente (alguien realizó el dibujo) o por accidente (alguien derramó pintura). Tanto los niños como los adultos se basaron en la forma para nombrar correctamente las figuras cuando pensaron que los dibujos habían sido creados intencionalmente y usaron 
con menos frecuencia la pista perceptual en los casos que pensaron que las imágenes habían sido creadas por accidente.

Bloom y Markson (1998) estudiaron el reconocimiento de la intención en situaciones en las que los niños debían nombrar sus propios dibujos. En esta investigación, niños de 36 y 48 meses tenían que dibujar un globo con un cordel y una paleta de caramelo, y a ellos mismos y al experimentador; el resultado fue pares de dibujos donde no se reflejaban diferencias en las formas. De este modo, los autores mostraron que los niños son capaces de identificar el referente de una imagen en base a la intención, aun cuando la forma de las figuras no permita distinguir esas intenciones.

La intención promueve el acceso a la comprensión simbólica más tempranamente si los niños reciben pistas explícitas, por ejemplo observando a un adulto dibujar. Preissler y Bloom (2008) demostraron que a los 30 meses los niños interpretan correctamente el contenido de un dibujo si observan al adulto dibujar mientras mira el objeto referente. La comprensión infantil se dificulta si el adulto mientras dibuja mira en otra dirección (a la pared) o si mira el objeto pero muestra a los niños un dibujo ya terminado.

Los niños son así sensibles a la intención en una relación social. Si el adulto enfatiza su intención referencial como dibujante tanto en forma gráfica (dibujando un objeto frente a los niños) como lingüística (enseñando la relación de representación entre sus marcas gráficas y el referente), niños aún más pequeños, de 24 meses, son capaces de relacionar dibujos simples en lápiz negro con los objetos que representan (Vivaldi \& Salsa, 2011).

La intención no es únicamente del dibujante sino también del usuario de una imagen. Utilizando una variación de la tarea de búsqueda de objetos diseñada por DeLoache (1987), Salsa y Peralta (2007) demostraron que los niños de 30 meses son exitosos en la tarea si la experimentadora señala explícitamente con qué intención debe ser usada la fotografía, esto es que la foto es fuente de información sobre el lugar donde buscar el objeto escondido en la habitación. Esta información fue una ayuda más potente que enseñar a los niños la correspondencia perceptual entre la fotografía y la habitación. A los 36 meses los niños resolvieron la tarea de búsqueda sin ningún tipo de guía del adulto.

Todos los estudios revisados ayudan a comprender cómo los niños pequeños infieren la función simbólica de las imágenes en experiencias comunicativas con otros que usan esas representaciones. En este aprendizaje cultural interpretar las intenciones referenciales y comunicativas de los adultos es primordial: los niños toman en cuenta la intención del dibujante y son conscientes de que las imágenes son creadas y utilizadas con intenciones específicas.

\section{CONCLUSIONES Y PERSPECTIVAS FUTURAS}

Milenios de evolución biológica y siglos de evolución cultural han configurado la mente humana para funcionar simbólicamente (Donald, 1991). Los bebés arriban al mundo equipados con habilidades perceptuales y cognitivas que los preparan para el funcionamiento simbólico. Una vez adquiridas, las representaciones externas permiten a los niños construir conocimientos sobre el mundo físico y social que los rodea y ser parte activa de él, en la medida que los adultos usan y otorgan a estos artefactos un gran valor cultural. Un desafío para los investigadores en desarrollo humano es determinar hasta qué punto la predisposición biológica y el aprendizaje cultural influyen en el desarrollo simbólico. Este artículo ha pretendido mostrar cómo en el desarrollo de la comprensión de representaciones figurativas la actividad cognitiva individual es tan crucial como la interacción con el mundo cultural, social y lingüístico.

A pesar que las fotografías y los dibujos figurativos son representaciones altamente similares a sus referentes, únicamente su procesamiento perceptivo es un logro muy precoz. En tanto que objetos que remiten a otra realidad, las imágenes comienzan a ser entendidas por los niños alrededor de los 18 
meses. Antes, no son más que objetos manipulables cuyo interés reside en sus propiedades físicas y no en su significado simbólico. Sólo de forma progresiva y en intercambios comunicativos con los adultos, fotografías y dibujos empiezan a ser interesantes no por lo que son sino por lo que denotan. La comprensión verdaderamente simbólica de las imágenes es producto de una construcción lenta y compleja que se extiende hasta los inicios de la escolaridad. Siguiendo a Freeman (2008), durante esta trayectoria evolutiva los niños construyen una teoría sobre las imágenes integrando conocimientos de la Física y de la Psicología folk (intuitiva): conocimientos sobre las imágenes como objetos (sus características y contenido) y sobre las intenciones de las personas que las crean y utilizan (teoría de la mente).

Restan todavía importantes interrogantes por resolver acerca del devenir de este proceso. En primer lugar, el desarrollo de la comprensión de las imágenes no culmina con el descubrimiento de su naturaleza dual, de su dimensión simbólica más allá de su apariencia concreta. Los niños pequeños focalizan la atención en qué es lo que la imagen representa y no en cómo lo hace, esto es en las propiedades estéticas de la imagen, en su composición, estilo y expresión. El reconocimiento de las propiedades estéticas, una adquisición que se inicia en los años preescolares y se extiende hasta la adolescencia temprana (cf., Szechter \& Liben, 2007; Winner, 2006), es un área poco explorada en los estudios sobre comprensión de fotografías y dibujos.

En segundo lugar, la mayor parte de las investigaciones se han centrado en explicar cuándo los niños interpretan la relación imagen - referente, identificando los mecanismos perceptuales y cognitivos que hacen posible esta comprensión. Sin embargo, las imágenes en sí no son más que objetos inanimados, son las personas quienes las crean, utilizan e interpretan y les otorgan un significado y función. En este sentido, Freeman (2008) postula que la comprensión de las imágenes involucra el conocimiento de las relaciones entre imagen y referente pero además entre imagen y artista (productor) y entre imagen y observador (receptor), cobrando así un lugar central las intenciones referenciales y comunicativas incorporadas en el símbolo. Un aspecto crucial de las imágenes es "... [que ellas son]... una manifestación intencional de la mente" (Wollheim, 1993, citado en Freeman, 2008, p. 33), de la mente del artista, de la mente del observador y de sus interconexiones. El dominio de esta dimensión intencional es todavía una cuestión pendiente de un análisis más exhaustivo en futuras investigaciones.

En tercer lugar, enfatizar la influencia de la intención permite correr el foco de interés hacia el contexto social. Si bien siguiendo una tradición neo-vygotskyana autores como Gauvain (2001) y Tomasello (1999, 2003) sostienen que los niños están expuestos a las herramientas simbólicas de la cultura en sus actividades cotidianas y que el aprendizaje cultural es un mecanismo que permite que estas herramientas sean comprendidas, nuevos estudios son necesarios para dilucidar los efectos de la experiencia social y simbólica en el conocimiento de representaciones externas distintas del lenguaje. Por ejemplo, qué características específicas del entorno de los niños explican la relación entre nivel socioeconómico y comprensión de imágenes o qué estrategias de aprendizaje los padres naturalmente despliegan cuando enseñan a sus hijos la naturaleza simbólica de diferentes clases de representaciones figurativas.

Por último, gran parte de los conocimientos que los niños pequeños y en edad preescolar aprenden sobre el mundo no es producto de la experiencia directa sino de su exposición cotidiana a una rica variedad de imágenes en fotografías, revistas y libros, la televisión y el video. En el hogar, los adultos utilizan naturalmente estas imágenes como un instrumento para la conversación y el aprendizaje. Recientemente, una serie de investigaciones han comenzado a centrar su interés en cuándo y cómo los niños comienzan a adquirir información nueva a través de ilustraciones en libros y a transferir y gene- 
ralizar esa información a la realidad, ya sea en el aprendizaje de palabras (Ganea et al., 2008; Ganea et al., 2009) como de conceptos biológicos simples (Ganea, Ma \& DeLoache, en prensa; Tare et al., 2010). La profundización en esta línea de trabajo posee importantes implicancias prácticas pudiendo contribuir al diseño de estrategias y recursos de enseñanza apropiados para edades tempranas.

En suma, adoptar una perspectiva teórica que considere en forma conjunta la actividad de los niños y las pautas evolutivas que la encuadran como los mecanismos sociales que permiten el aprendizaje y desarrollo del conocimiento de las imágenes permitirá entender mejor el complejo proceso por el cual una imagen vale más que mil palabras.

\section{REFERENCIAS BIBLIOGRÁFICAS}

Baldwin, D.A. (2000). Interpersonal understanding fuels knowledge acquisition. Current $\mathrm{Di}$ rections in Psychological Science, 9, 40-45. doi:10.1111/1467-8721.00057.

Barrera, M.E. \& Maurer, D. (1981). Recognition of mother's photographed face by the threemonth-old. Child Development, 52, 714-716. doi:10.2307/1129196.

Bloom, P. \& Markson, L. (1998). Intention and analogy in children's naming of pictorial representations. Psychological Science, 9, 200204. doi: 10.1111/1467-9280.00038.

Bovet, D. \& Vauclair, J. (2000). Picture recognition in animals and humans. Behavioural Brain Research, 109, 143-165. doi: 10.1016/ S0166-4328(00)00146-7.

Callaghan, T.C. (2000). Factors affecting children's graphic symbol use in the third year: Language, similarity, and iconicity. Cognitive
Development, 15, 185-214. doi:10.1016/S088 5-2014(00)00026-5.

Callaghan, T.C. (2008). The origins and development of pictorial symbol functioning. En C. Milbrath \& H.M. Trautner (Eds.), Children's understanding and production of pictures, drawings, and art (pp. 21-32). Cambridge, MA: Hogrefe.

Callaghan, T.C., Moll, H., Rakoczy, H., Warneken, F., Liszkowski, U., Behne, T. \& Tomasello, M. (2011). Early social cognition in three cultural contexts. Monographs of the Society for Research in Child Development, 76, 1-142. doi: 10.1111/j.1540-5834. 2011.00603.x.

Callaghan, T.C. \& Rankin, M. (2002). Emergence of graphic symbol functioning and the question of domain specificity: A longitudinal training study. Child Development, 73, 359-376. doi: 10.1111/1467-86 24.00412.

Callaghan, T.C. \& Rochat, P. (2003). Traces of the artist: Sensitivity to the role of the artist in children's pictorial reasoning. British Journal of Developmental Psychology, 21, 415-445. doi:10.1348/026151003322277784.

Callaghan, T.C., Rochat, P., MacGillivray, T. \& MacLellan, C. (2004). Modeling referential actions in 6- to 18-month-old infants: A precursor to symbolic understanding. Child Development, 75, 1733-1744. doi:10.1111/j.b1 467-8624.2004.00813.x.

DeLoache, J.S. (1987). Rapid change in the symbolic functioning of very young children. Science, 238, 1556-1557. doi:10.1126/science. 2446392.

DeLoache, J.S. (1991). Symbolic functioning in very young children: Understanding of pictures and models. Child Development, 62, 736-752.doi:10.2307/1131174.

DeLoache, J.S. (1995). Early understanding and use of symbols: The model model. Current 
Directions in Psychological Science, 4, 109113. doi:10.1111/1467-8721.ep10772408.

DeLoache, J.S. (2002). The symbol-mindedness of young children. En W. Hartup \& R.A. Weinberg (Eds.), Child psychology in retrospect and prospect: In celebration of the 75th anniversary of the Institute of Child Development (Vol. 32, pp. 73-101). Mahwah, NJ: Erlbaum.

DeLoache, J.S. \& Burns, N.M. (1994). Early understanding of the representational function of pictures. Cognition, 52, 83-110. doi: 10.1016/ 0010-0277(94)90063-9.

DeLoache, J.S., Pierroutsakos, S.L, Uttal, D.H., Rosengren, K.S. \& Gottlieb, A. (1998). Grasping the nature of pictures. Psychological Science, 9, 205-210. doi:10.1111/1467-9280.00 039.

DeLoache, J.S., Strauss, M.S. \& Maynard, J. (1979). Picture perception in infancy. Infant Behavior and Development, 2, 77-89. doi:10. 1016/S0163-6383(79)80010-7.

Deregowski, J. (1989). Real space and represented space: Cross-cultural perspectives. Behavioral and Brain Science, 12, 51-119. doi:10. 1017/S0140525X00024286.

Diamond, A. (2002). Normal development of prefrontal cortex from birth to young adulthood: Cognitive functions, anatomy, and biochemistry. En D.T. Stuss, \& R.T. Knight (Eds.), Principles of frontal lobe function (pp. 466503). London: Oxford University Press.

Dirks, J. \& Gibson, E. (1977). Infant perception of similarity between live people and their photographs. Child Development, 48, 124-130. doi:10.2307/1128890.

Donald, M. (1991). Origins of the modern mind. Cambrigde, MA: Harvard University Press.

Flavell, J.H., Flavell, E.R., Green, F.L. \& Korfmacher, J.E. (1990). Do young children think of television images as pictures or real objects? Journal of Broadcasting and Electronic Media, 34, 399-419. doi:10.1080/ 08838 159009386752.

Freeman, N.H. (2008). Pictorial competence generated from crosstalk between core domains. En C. Milbrath \& H.M. Trautner (Eds.), Children's understanding and production of pictures, drawings, and art (pp. 33-52). Cambridge, MA: Hogrefe.

Freeman, N.H. \& Adi-Japha, E. (2008). Pictorial intention, action and interpretation. En C. Lange-Kuttner \& A. Vinter \& (Eds.), Drawing and the non-verbal mind: A lifespan perspective (pp. 104-120). Cambridge: Cambridge University Press.

Freeman, N.H. \& Sanger, D. (1993). Language and belief in critical thinking: Emerging explanations of pictures. Exceptionality Education Canada, 3, 43-58.

Ganea, P.A., Allen, M.L., Butler, L., Carey, S. \& DeLoache, J.S. (2009). Toddler's referential understanding of pictures. Journal of Experimental Child Psychology, 104, 283-295. doi: 10.1016/j.jecp.2009.05.008.

Ganea, P.A., Bloom Pickard, M. \& DeLoache, J.S. (2008). Transfer between picture books and the real world by very young children. Journal of Cognition and Development, 9, 46-66. doi:10. 1080/15248370701836592.

Ganea, P.A., Ma, L. \& DeLoache, J.S. (en prensa). Young children's learning and transfer of biological information from picture books to real animals. Child Development. doi: 10.11 11/j.1467-8624.2011.01612.x.

Gauvain, M. (2001). The social context of cognitive development. New York: Guilford.

Gelman, S.A. \& Ebeling, K.S. (1998). Shape and representational status in children's early naming. Cognition, 66, B35-B47. doi: 10.101 6/S0010-0277(98)00022-5http://dx.doi.org/ 
$10.1016 \%$ 2FS0010-0277\% 2898\%29000225.

Gentner, D. (2010). Bootstrapping the mind: Analogical processes and symbol systems. Cognitive Science, 34, 752-775. doi: 10.1111/j. 1551-6709.2010.01114.x.

Goodman, N. (1976). Languages of art: An approach to a theory of symbols. Indianapolis, IN: Hackett Publishing.

Gopnik, A. (1996). The scientist as child. Philosophy of Science, 63, 485-514. doi:10.1086/ 289970.

Harris, P.L., Kavanaugh, R.D. \& Dowson, L. (1997). The depiction of imaginary transformations: Early comprehension of a symbolic function. Cognitive Development, 12, 1-19. doi:10.1016/S0885-2014(97)90028-9.

Hochberg, J. (1997). The affordance of perceptual inquiry: Pictures are learned from the world, and what that fact might mean about perception quite generally. The Psychology of Learning and Motivation, 36, 15-44. doi:10.1016/S00797421(08)60280-7.

Karmiloff-Smith, A. (1992). Beyond modularity: A developmental perspective on cognitive science. Cambridge, MA: MIT Press.

Liben, L.S. (1999). Developing an understanding of external spatial representations. En I.E. Sigel (Ed.), Development of mental representation. Theories and applications (pp. 297-321). Mahwah, NJ: Erlbaum.

Martí, E. (2003). Representar el mundo externamente [Represent the world externally]. Madrid: Machado Libros.

Morra, S. (2008). Memory components and control processes in children's drawing. En C. Milbrath \& H.M. Trautner (Eds.), Children's understanding and production of pictures, drawings, and art (pp. 53-85). Cambridge: Hogrefe.
Namy, L.L. \& Waxman, S.R. (2005). Symbols redefined. En L.L. Namy (Ed.), Symbol use and symbolic representation (pp. 269-278). Mahwah, NJ: Erlbaum.

Peralta, O.A. \& Salsa, A.M. (2011). Instrucción y desarrollo en la comprensión temprana de fotografías como objetos simbólicos [Instruction and development in early comprehension of photographs as symbolic objects]. Anales de Psicología, 27, 118-125.

Perner, J. (1991). Understanding the representational mind. Cambridge, MA: MIT Press.

Piaget, J. \& Inhelder, B. (1956). The child's conception of space. London: Routledge and Kegan Paul.

Pierroutsakos, S.L. \& DeLoache, J.S. (2003). Infants' manual exploration of pictorial objects varying in realism. Infancy, 4, 141-156. doi: 10.1207/S15327078IN0401_7.

Pierroutsakos, S.L., DeLoache, J.S., Gound, M. \& Bernard, E.N. (2005). Very young children are insensitive to picture- but not to object-orientation. Developmental Science, 8, 326-332. doi:10.1111/j.1467-7687.2005.00420.x.

Preissler, M.A. \& Bloom, P. (2008). Two-year-olds use artist intention to understand drawings. Cognition, 106, 512-518. doi: 10.1016/ j.c ogn ition.2007.02.002.

Preissler, M.A. \& Carey, S. (2004). Do both pictures and words function as symbols for 18and 24-month-old children? Journal of Cognition and Development, 5, 185-212. doi:10. 1207/s15327647jcd0502_2.

Robinson, E.J., Nye, R. \& Thomas, G.V. (1994). Children's conceptions of the relationship between pictures and their referents. Cognitive Development, 9, 165-191. doi:10.1016/08852014(94)90002-7.

Rochat, P. \& Callaghan, T.C. (2005). What drives symbolic development? The case of pictorial 
comprehension and production. En L.L. Namy (Ed.), Symbol use and symbolic representation (pp. 25-46). Mahwah, NJ: Erlbaum.

Salsa, A.M. (en prensa). Factores que influyen en la comprensión temprana de imágenes: Similitud perceptual y nivel socioeconómico [Factors affecting early understanding of pictures: Perceptual similarity and socioeconomic status]. Infancia y Aprendizaje.

Salsa, A.M. \& Peralta, O.A. (2007). Routes to symbolization: Intentionality and correspondence in early understanding of pictures. Journal of Cognition and Development, 8, 7992. doi:10.1207/s15327647jcd0801_4.

Schmitt, K.L. \& Anderson, D.R. (2002). Television and reality: Toddlers' use of visual information from video to guide behavior. Media Psychology, 4, 51-76. doi:10.1207/S15 32785XMEP0401_03.

Simcock, G. \& DeLoache, J.S. (2006). Get the picture? The effects of iconicity on toddlers' reenactment from picture books. Developmental Psychology, 42, 1352-1357. doi:10.10 37/0012-1649.42.6.1352.

Slater, A., Rose, D. \& Morison, V. (1984). Newborn infants' perception of similarities and differences between two- and three-dimensional stimuli. British Journal of Developmental Psychology, 2, 287-294. doi:10.1111/j.2044 835X.1984.tb00936.x.

Szechter, L.E. \& Liben, L.S. (2004). Parental guidance in preschoolers understanding of spacial-graphic representations. Child Development, 75, 869-885. doi:10.1111/j.1467-8624. 2004.00711.x.

Szechter, L.E. \& Liben, L.S. (2007). Children's aesthetic understanding of photographic art and the quality of art-related parent-child interactions. Child Development, 78, 879-894. doi: 10.1111/j.1467-8624.2007.01038.x.
Tare, M., Chiong, C., Ganea, P.A. \& DeLoache, J.S. (2010). Less is more: How manipulative features affect children's learning from picture books. Journal of Applied Developmental Psychology, 31, 395-400. doi: 10.1016/ j.appdev. 2010.06.005.

Tomasello, M. (1999). The cultural origins of human cognition. Cambridge,MA: Harvard University Press.

Tomasello, M. (2003). Constructing a language: A usage-based theory of language acquisition. Cambridge, MA: Harvard University Press.

Troseth, G.L. (2003). Getting the clear picture: Young children's understanding of a televised image. Developmental Science, 6, 247-253. doi:10.1111/1467-7687.00280.

Troseth, G.L. \& DeLoache, J.S. (1998). The medium can obscure the message: Young children's understanding of video. Child Development, 69, 950-965. doi:10.2307/1132355.

Vivaldi, R.A. \& Salsa, A.M. (2011, Agosto). La influencia de la intencionalidad referencial en la comprensión temprana de dibujos [The influence of referential intentionality in early understanding of drawings]. Trabajo presentado en la XIII Reunión Nacional y II Encuentro Internacional de la Asociación Argentina de Ciencias del Comportamiento, Libertador San Martín, Prov. de Entre Ríos.

Vygotsky, L.S. (1978). Mind in society: The development of higher psychological processes. Cambridge, MA: Harvard University Press.

Werner, H. \& Kaplan, B. (1963). Symbol formation: An organismic-developmental approach to language and the expression of thought. Oxford, NY: Wiley.

Winner, E. (2006). Development in the arts: Drawing and music. En D. Kuhn \& R. Siegler (Eds.), Handbook of child psychology (Vol. 2, pp. 859- 
904). New Jersey: Wiley. doi: 10.1002/97804 70147658.

Woodward, A.L. (1999). Infant's ability to distinguish between purposeful and non-purposeful behaviors. Infant Behavior and Development, 22, 145-160. doi:10.1016/S0163-6383(99)000 07-7.

Yonas, A., Granrud, C.E., Chov, M.H. \& Alexander, A.J. (2005). Picture perception in infants:
Do 9-month-olds attempt to grasp objects depicted in photographs? Infancy, 8, 147-166. doi:10.1207/s15327078in0802_3.

Zaitchik, D. (1990). When representations conflict with reality: the preschooler's problem with false beliefs and "false" photographs. Cognition, 35, 41-69. doi: 10.1016/0010-0277(90) 90036-J.

Instituto Rosario de Investigaciones en Ciencias de la Educación (IRICE) Consejo Nacional de Investigaciones Cientificas y Técnicas (CONICET) Rosario - Prov. de Santa Fe República Argentina

Fecha de recepción: 20 de septiembre de 2011 Fecha de aceptación: 3 de abril de 2012 
